\title{
Verzeichnis der Abkürzungen für beide Teile des Werkes
}

\author{
BGB . . . . . . Bürgerliches Gesetzbuch \\ BGBl . . . . . . Bundesgesetzblatt \\ BGH ... . . . . Entscheidungen des Bundesgerichtshofs in Straf- \\ sachen (amtliche Sammlung) \\ DJ . . . . . . . . Deutsche Justiz \\ DRZ . . . . . . Deutsche Rechtszeitschrift \\ E . . . . . . . Entscheidungen des Reichsgerichts in Strafsachen \\ GVG . . . . . . . Gerichtsverfassungsgesetz \\ HGB ........ Handelsgesetzbuch \\ JGG . . . . . . Jugendgerichtsgesetz \\ JR . . . . . . . Juristische Rundschau \\ JW . . . . . . Juristische Wochenschrift \\ $\mathrm{JZ} \ldots \ldots$. . . . Juristenzeitung \\ LK . . . . . . . . Leipziger Kommentar zum StGB (Ebermayer, \\ Lobe, Rosenberg) \\ MDR . . . . . . . . Monatsschrift für Deutsches Recht \\ NJW . . . . . . . Neue Juristische Wochenschrift \\ OLG ....... Oberlandesgericht \\ PStG . . . . . . Personenstandsgesetz \\ RG . . . . . . . . Reichsgericht \\ RGBl ....... Reichsgesetzblatt \\ StGB ........ Strafgesetzbuch \\ StPO ........ Strafprozeßordnung \\ StVO ...... Straßenverkehrsordnung \\ ZPO . ...... Zivilprozeßordnung
}

